\title{
The efficacy of platelet rich plasma as adjuvant therapy in the treatment of cryptosporidiosis in experimentally infected immunosuppressed rats
}

Original
Article

\author{
Walaa A El-Kholy ${ }^{1}$, Shimaa A Elgohary², Amal A El Kholy ${ }^{3}$, Ayman M El-Ashkar ${ }^{4,5}$ \\ Departments of Medical Parasitology, Faculty of Medicine (Girls), Al-Azhar University ${ }^{1}$ \\ and Ain shams University 4 , Pathology, Faculty of Medicine², and Clinical Pharmacy, Faculty \\ of Pharmacy ${ }^{3}$, Ain Shams University, Cairo, Egypt, and Basic Medical Science ${ }^{5}$, College of \\ Medicine, University of Bisha, Bisha, KSA
}

\begin{abstract}
Background: Cryptosporidium species are zoonotic opportunistic coccidian parasites that could cause disseminated life-threatening infection in the immunocompromised host. Unfortunately, few available drugs effectively eradicate the infectious oocyst with limited availability in developing countries. Although Nitazoxanide (NTZ) is the drug of choice for the treatment of cryptosporidiosis, it has limited efficacy in malnourished and immunocompromised patients. Moreover, platelet-rich plasma (PRP) successfully ameliorated the hepatic granuloma size in patients with parasitic schistosomiasis mansoni.

Objective: This study aims to test the potential therapeutic effect of PRP versus the currently used NTZ, and/or using PRP as adjuvant therapy.

Material and Methods: Sixty-five immunosuppressed rats were divided into 5 groups: non-infected as negative control (GI), infected non-treated as the positive control (GII), infected with Cryptosporidium spp. and treated with either intraperitoneal PRP (GIII), or NTZ (GIV), or a combination of intraperitoneal PRP and NTZ (GV). Parameters used for evaluation of the therapeutic efficacy included parasitological examination, histopathological examination of ileocaecal and liver specimens, and quantitative analysis of reduced glutathione (GSH) and malondialdehyde (MDA) for evaluation of oxidative stress markers, glutamic-oxaloacetic transaminase (SGOT), and glutamic pyruvic transaminase (SGPT) for evaluation of liver functions.

Results: Parasitological and histopathological examinations revealed minimal improvement in GIII, marked improvement in GIV, and the best results were recorded in GV. The administration of PRP in GIII produced no significant changes in GSH, MDA, SGOT compared to positive control GII. Treatment with NTZ in GIV, and in addition to PRP in GV showed significant difference $(P<0.05)$ compared to GII regarding serum results of GSH, MDA, and SGOT with the best results recorded in GV. GIV and GV showed reduction of serum levels of SGPT although there was statistically insignificant difference between the study groups. Conclusion: PRP could be used as a potential adjuvant therapy with NTZ to ameliorate the pathologic and inflammatory effects of cryptosporidiosis on the ileocaecal region. It also improves liver function in the immunocompromised hosts.
\end{abstract}

Keywords: cryptosporidiosis; glutathione; liver function tests; malondialdehyde; nitazoxanide; platelet-rich plasma.

Received: 18 March, 2021, Accepted: 3 July, 2021.

Corresponding Author: Aymen M. El-Ashkar, Tel.: +20 1030876995, E-mail: aymanpara@yahoo.com

Print ISSN: 1687-7942, Online ISSN: 2090-2646, Vol. 14, No. 2, August, 2021.

\section{INTRODUCTION}

The genus Cryptosporidium and its species belong to the phylum Apicomplexa. They are intestinal coccidian protozoa that mainly inhabit the brush border of the small intestine acquiring the unusual position of being intracellular, but extra-cytoplasmic ${ }^{[1]}$. Cryptosporidiosis is a globally distributed zoonotic disease-causing enteritis and aqueous diarrhea ${ }^{[2]}$. Implicated species are transmitted via consumption of contaminated food or drink with sporulated oocysts, inhalation of oocysts from the soil, and selfinfection $^{[3,4]}$.
In 2015, 27 species of Cryptosporidium were characterized $^{[5]}$. Despite reports on infection in man by several species, the majority of human cryptosporidiosis proved to be due to C. hominis and $C$. parvum ${ }^{[6-8]}$. Cryptosporidiosis may cause serious complications in immunocompromised patients including severe diarrhea with subsequent dehydration and electrolyte imbalance, hepatic and respiratory problems ${ }^{[9]}$. There are several major mechanisms responsible for the associated diarrhea, the most important of which is morphologic atrophy of small intestinal villi, blunting and fusion of the villi, in addition to inflammatory infiltrates in the lamina 
propria of the intestinal wall[10]. It is noteworthy that cryptosporidiosis was shown to stimulate apoptosis in cultured epithelia of the intestinal and biliary tracts ${ }^{[11]}$. Additionally, cryptosporidiosis parvum induces an up-regulation in the expression of cyclooxygenase-2 (Cox-2) in the epithelial cells ${ }^{[12]}$, besides stimulating the release of pro-inflammatory cytokines such as interleukin (IL)-1, IL-6, IL-8, and tumor necrosis factor- $\alpha(\mathrm{TNF}-\alpha)^{[13]}$.

Although, the worldwide nature of cryptosporidiosis is well established, there are still few limited options for treatment. Supportive therapy and specific treatment by NTZ, which is the only approved drug by the Food and Drug Administration (FDA) in the United States, are still the only available solution for serious infections. Unfortunately, NTZ has restricted efficacy in poorly nourished children and seems to have no efficacy in immunocompromised patients ${ }^{[14-17]}$.

It was established that PRP is composed of a high concentration of autologous platelets in a small amount of centrifugated plasma ${ }^{[18]}$. Platelets have a basic role in hemostasis and are a natural origin for growth factors (GFs) production. Growth factors, stored within platelet $\alpha$-granules, include platelet-derived growth factor (PDGF), insulin-like growth factor (IGF), vascular endothelial growth factor (VEGF), platelet-derived angiogenic factor (PDAF), and transforming growth factor-beta (TGF- $\beta$ ). Thrombin, calcium chloride, or collagen are important stimulants that could activate the platelets to release the GFs. These GFs are capable of stimulating angiogenesis and increasing fibroblast cell differentiation ${ }^{[18,19]}$. The rate of wound healing of soft tissues could be doubled or tripled under the influence of these $\mathrm{GFS}^{[20]}$. Furthermore, platelets produce many important factors like fibronectin, vitronectin, sphingosine 1-phosphate, that have an extremely significant role in wound healing ${ }^{[21]}$. These properties initiated the proposal of medical usage of PRP to promote soft tissue healing ${ }^{[18,19]}$. Although, there is no accessible effective anti-fibrotic therapy ${ }^{[22]}$, PRP was shown to reduce chemically-induced liver fibrosis in experimental animals ${ }^{[23-25]}$. As a parasitic treatment, PRP proved to alleviate liver fibrosis in murine schistosomiasis mansoni ${ }^{[26]}$. Besides, PRP products are easy and inexpensive to prepare ${ }^{[27]}$.

Oxidative stress occurs due to a change in the balance between oxidantand antioxidant cellular agents, and it is caused by overproduction of reactive oxygen substrates (ROS). A balance between ROS and primary antioxidant products, i.e., superoxide dismutase (SOD), catalase (CAT), and glutathione peroxidase (GSH), is needed for preventing damage by oxidative stress. There are very few reports in the literature documenting the role of ROS in the pathogenesis of C. parvum infection ${ }^{[28-30]}$. Experimental infection of immunocompromised Swiss albino mice with $C$. parvum caused an elevation in lipid peroxidation products like MDA and reduction of GSH,
CAT, and SOD at the peak of infection, which proves the role of ROS in the pathogenesis of experimental $C$. parvum infection in mice ${ }^{[31]}$.

Keeping the previous layout in mind, our study aimed to evaluate the synergistic effect of PRP as an adjuvant therapy with NTZ, to revert the pathologic changes in the ileocaecal region, livers, and portal tracts of white albino rats that were subjected to immunosuppression then infection with Cryptosporidium oocysts. In addition to evaluation of liver functions and oxidative stress markers.

\section{MATERIAL AND METHODS}

This experimental study was performed in the biological unit of Theodor Bilharz Research Institute (TBRI) during the period from September 2020 to March 2021. Pathology sections were prepared and examined in the Pathology Department Laboratory at Ain-Shams University Hospital.

Animals: Sixty-five laboratory rats of Sprague Dawley strain, $\sim 10$ weeks old, weighing 130-150 gm, were purchased from the Animal House of TBRI. The animals were kept in plastic cages with clean woodchip bedding, in well-ventilated, sanitary, conditioned rooms with the mean temperature $\left(27 \pm 2^{\circ} \mathrm{C}\right)$, away from direct sunlight. Animals were provided by chow and water ad lib.

Study groups: Fifty immunosuppressed rats were divided into 5 groups; 10 in each. Groups I (non-infected) and II (infected with Cryptosporidium oocysts, nontreated) were used as negative and positive controls, respectively. Groups III-V included infected rats treated with intraperitoneal PRP, NTZ, and combined therapy, respectively. Fifteen non-immunosuppressed rats served for PRP preparation.

Immunosuppression: Rats were immunosuppressed by oral administration of dexamethasone sodium phosphate (Dexazone) with a dose of $0.25 \mathrm{ug} / \mathrm{g} /$ day for two weeks by gavage technique using an esophageal tube; and was maintained by a weekly dose during the whole experiment for all the study groups ${ }^{[32]}$.

Infection: After two weeks, immunosuppressed rats were orally infected by a suspension of $10^{5}$ Cryptosporidium oocysts in $200 \mu \mathrm{L}$ PBS, by gavage using an esophageal tube ${ }^{[3]}$. Cryptosporidium oocysts were kindly obtained from the Animal Research Institute in Giza governorate, Egypt.

Drug and PRP preparation: NTZ was obtained from a local pharmacy in the form of powder to prepare 100 mg suspension/5 ml (Nanazoxide ${ }^{\circledR}$ ). To prepare PRP, 15 non-immunosuppressed rats were anesthetized using ether. After laparotomy, four ml venous blood 
was collected from the inferior vena cava in tubes containing 3.2\% sodium citrate (Merck, Darmstadt, Germany). Centrifugation of blood samples was performed at $400 \mathrm{~g}$ for $10 \mathrm{~min}$. The supernatant was centrifuged again at $800 \mathrm{~g}$ for $10 \mathrm{~min}$. From each tube, two-thirds of the serum were discarded from the top, and the remaining pooled portions were accepted as $\mathrm{PRP}^{[34]}$. After the aforementioned procedure, $\sim 15 \mathrm{ml}$ of PRP was obtained.

Therapeutic doses: Rats of GIII received PRP in a dose of $0.5 \mathrm{ml} / \mathrm{kg}$ by intraperitoneal injection twice weekly for 4 weeks starting one week post-infection (pi) ${ }^{[24]}$. Rats of GIV received $65 \mathrm{mg}$ of NTZ oral suspension. The drug was administered daily for 4 weeks starting oneweek pi. The doses were adjusted by an extrapolation table for the therapeutic doses of man and animal ${ }^{[35]}$. Whereas GV received a similar regimen and doses of PRP and NTZ.

Parasitological examination: To ensure rats' infection, stool samples were obtained a week after inoculation with oocyst for microscopic examination using the oil immersion lens (x100) after staining the stool smears by modified Zeihl Neelsen (MZN) stain ${ }^{[36]}$. Parasite load was calculated by counting the number of Cryptosporidium oocysts in the fecal pellets collected from infected rats at $7^{\text {th }}, 14^{\text {th }}, 21^{\text {st }}, 28^{\text {th }}$, and $35^{\text {th }}$ day pi. One mg stool pellet was weighed, then preserved in $1 \mathrm{ml}$ $10 \%$ formalin; the stool suspension was concentrated by centrifugation at $500 \mathrm{~g}$ for $10 \mathrm{~min}$. The oocysts were counted in $1 \mathrm{ml}$ of stool sample by staining $100 \mathrm{ul}$ of stool sediment by MZN and examining microscopically (x100). The average of 3 counts multiplied by 10 equaled the number of oocysts in $1 \mathrm{ml}$ of stool ${ }^{[37]}$. The number of oocysts was expressed per gram of feces ${ }^{[38]}$. Oocyst shedding one week after inoculation was considered a sure sign of viability and establishment of infection

Measurement of serum liver enzymes and oxidative stress markers: One ml venous blood was collected from each rat from the retro-orbital vein 4 weeks after the establishment of infection at the end of the treatment regimen. Levels of GSH${ }^{[39]}$, MDA ${ }^{[40]}$, SGOT and SGPT $^{[41]}$ were measured using Sigma Diagnostic kits (USA).

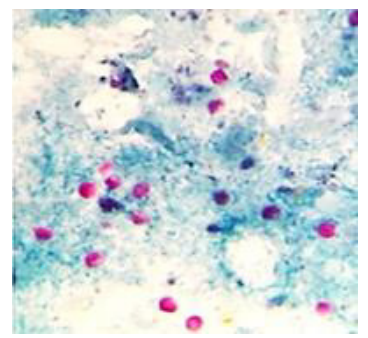

Fig. 1. Cryptosporidium spp. oocyst (red spots), stained by MZN (X1000).
Histopathological examination: All rats were euthanized 4 weeks pi to remove the ileocecal region of the small intestine and liver with the portal tracts. The specimens were fixed in $10 \%$ buffered formalin, embedded in paraffin wax blocks, sectioned, and stained by Hematoxylin and Eosin $(\mathrm{H} \& \mathrm{E})^{[42]}$.

Statistical analysis: Data were expressed as mean \pm standard deviation (SD). Differences between groups were determined using a one-way ANOVA and post hoc Tukey`s multiple comparison tests. The level of significance was accepted at $P$ value $<0.05$.

Ethical consideration: This study was approved by the Scientific Research Ethics Committee of TBRI. The internationally valid guidelines were applied for all animal experiments after acceptance by the institutional ethical committee.

\section{RESULTS}

Parasitological studies: After inoculation of rats with Cryptosporidium spp. oocysts (Fig. 1), fecal pellets were collected from GII (infected non-treated) at different days pi to determine the number of Cryptosporidium spp. oocysts/gm of feces on each day (Fig. 2). It was observed that oocysts shedding started from the 7 th day pi with $715 \pm 48.65 \times 10^{3}$ oocysts/gm of feces.

Table (1) shows the therapeutic effects of drugs used on oocysts shedding in collected stool pellets. The number of Cryptosporidium spp. oocysts/gm of feces that were shed by GII rats on the $35^{\text {th }}$ day of infection was $2292.8 \pm 227.32 \times 10^{3}$ oocysts. There was $59.17 \%$, $65.14 \%$ and $71.32 \%$ reduction of oocyst shedding in GIII, GIV and GV compared to GII, respectively. It is worth mentioning that the mortality rate was around $10 \%$ in all the study groups.

Histopathological examination of ileocaecal and liver specimens: In GI, sections of the small intestine at ileocecal junction showed normal small intestinal mucosa with normal villous architecture length and width. A well-formed intact brush border was detected

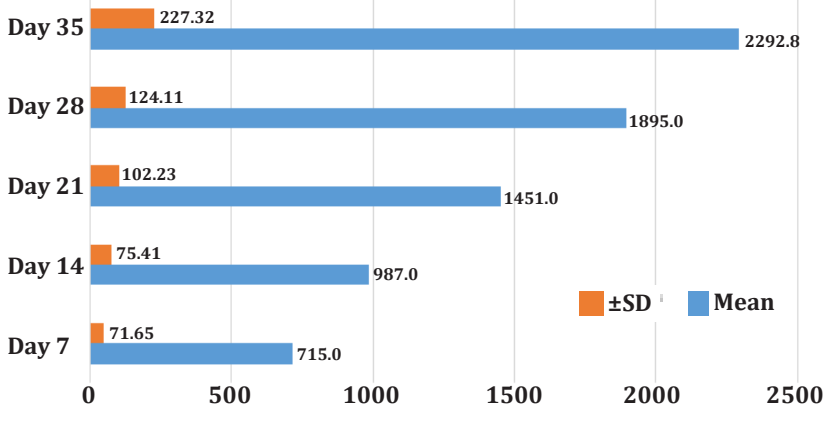

Fig. 2. The number of shed Cryptosporidium spp. oocysts (mean \pm SD) $\times 10^{3} /$ gm of feces in the infected non-treated group (GII) on different days pi. 
Table 1. The number of Cryptosporidium spp. oocysts (mean \pm SD) $\mathrm{x} 10^{3} / \mathrm{gm}$ of feces at the $35^{\text {th }}$ day pi in the different study groups with the estimation of the percentage of reduction compared to GII.

\begin{tabular}{lcc}
\hline \hline Groups & $\begin{array}{c}\text { Number of oocysts shedding at day } \mathbf{3 5} \mathbf{~ p i} \\
\text { Mean } \pm \mathbf{S D ~} \mathbf{X} \mathbf{1 0}^{\mathbf{3}}\end{array}$ & \% of reduction \\
\hline Group II & $2292.8 \pm 227.32$ & -- \\
Group III & $936.18 \pm 29.38$ & 59.17 \\
Group IV & $799.2 \pm 45.19$ & 65.14 \\
Group V & $657.6 \pm 29.08$ & 71.32 \\
\hline \hline
\end{tabular}

with an average number of goblet cells. Hepatic sections showed normal hepatic architecture with the hepatocytes arranged in thin regular plates around the central vein and unremarkable portal tracts (Fig. 3).

In GII, the ileocecal junction of the small intestine revealed marked histopathological changes as a result of cryptosporidiosis. Variable grades of villous atrophy in addition to decreased villous height to crypt ratio and shortened broad villi were detected. Foci of mucosal ulceration were observed together with the depletion of goblet cells. Significant inflammatory infiltrate was also seen in the lamina propria composed mainly of plasma cells, lymphocytes, and macrophages with lymphoid aggregates. Examination of liver sections showed expanded portal tracts with moderate lymphoid infiltrate. Dispersed spotty necrosis foci were detected together with mild interface activity and mild fibrosing reaction forming porto-portal bridges (Fig. 4).

In GIII, there was minimal amelioration of the histopathological changes at the ileocecal junction.
A mild reduction in villous height to crypt ratio with moderate villous blunting was detected. Foci of mucosal ulceration were seen with mild exhaustion of goblet cells. Lamina propria showed moderate inflammatory infiltration. Liver sections showed foci of lobular activity with mildly dilated portal tracts and moderate lymphocytic infiltrate (Fig. 5).

In GIV, marked amelioration of the histopathological changes occurred. Restoration of normal villous architecture was detected and the ratio between villous height and the crypt became close to normal. Regular brush border and normal goblet cells were seen There were minimal surface mucosal erosions, and the mucosal lining showed a nearly normal pattern. The lamina propria showed a mild inflammatory reaction. The liver sections showed mild portal inflammatory infiltrate (Fig. 6).

In GV, the ileocecal junction showed remarkable amelioration of the histopathological changes, with preservation of the villous to crypt height ratio.
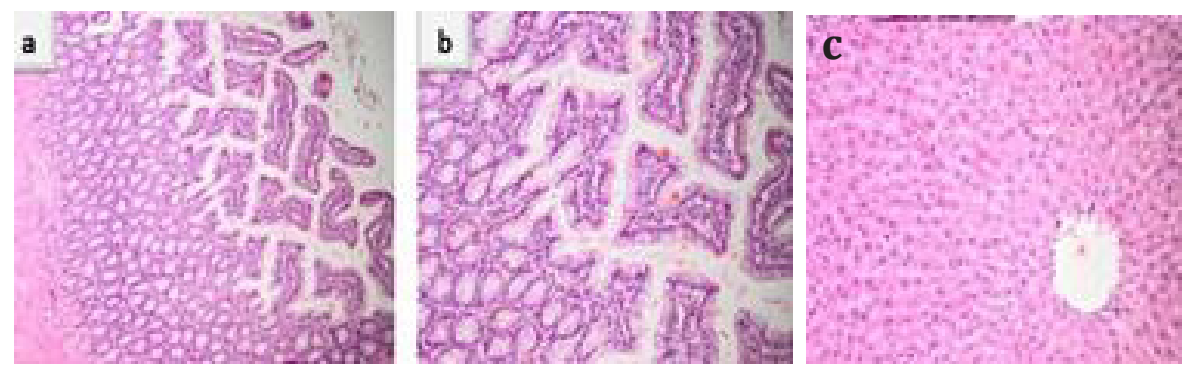

Fig. 3. (a, and b): Small intestine section of GI showing preserved architecture of the villi with intact brush border (H\&E stain x200). c): Liver section of G1 showing normal hepatic architecture (H\&E stain x 200).

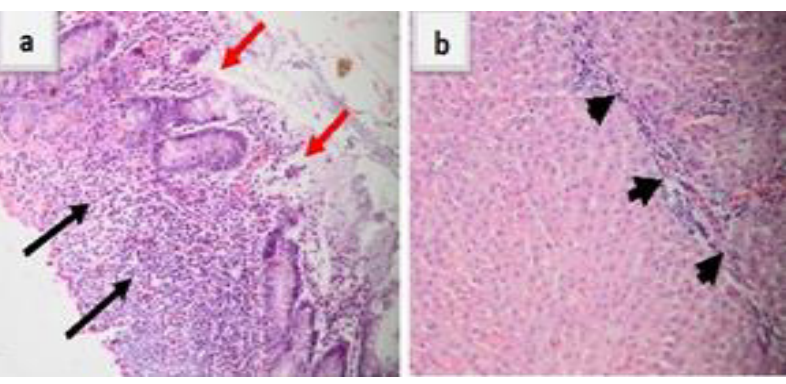

Fig. 4. a): Small intestinal section from GII showing variable grades of villous atrophy, mucosal ulceration, and goblet cell depletion (red arrows). The lamina propria contained significant inflammatory infiltrates with lymphoid aggregates (black arrows) (H\&E stain x 200). b): Liver section of GII showing dilated portal tracts with severe inflammation and porto-portal bridges with interface activity and moderate fibrosis (black arrow heads) (H\&E stain $\mathrm{x} 200$ ).
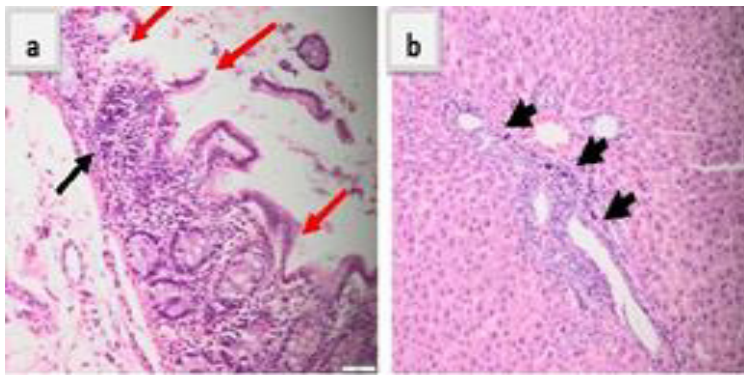

Fig. 5. a): Small intestinal section from GIII showing moderate villous blunting with foci of ulcerated mucosa (red arrows) and lamina propria with inflammatory infiltration (black arrow) (H\&E stain x200). b): Liver section showing foci of lobular activity with mildly dilated portal tracts and moderate lymphocytic infiltrate (black arrowheads) (H\&E stain x200). 
The normal villous architecture was restored. The mucosal lining, brush border, and goblet cells were nearly normal. The lamina propria showed minimal

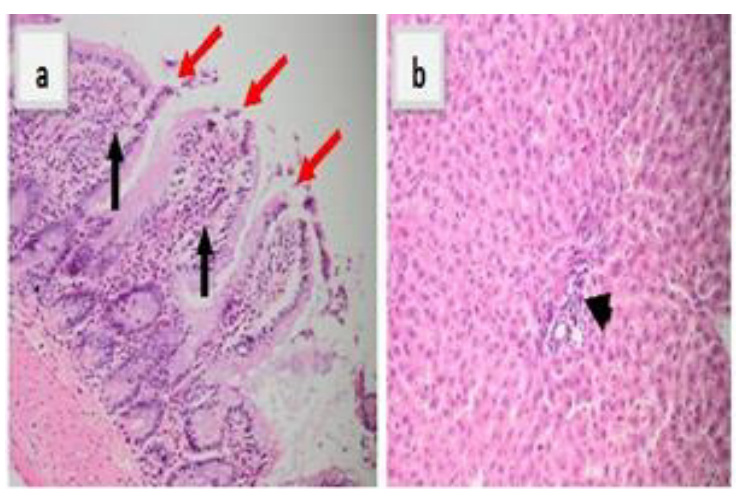

Fig. 6. a): Small intestinal section from GIV showing resumption of the normal villous architecture; the ratio between villous height and crypt were close to normal with focal minimal surface mucosa erosions (red arrows). The lamina propria showed mild inflammatory infiltration (black arrows) (H\&E stain x200). b): Liver sections showing mild portal inflammatory infiltrate (black-arrow head) (H\&E stain x200).

Biochemical analysis of serum GSH, MDA, SGOT, and SGPT: There was a significant difference between all the study groups regarding serum GSH, and SGOT $(P<0.01)$, and serum MDA $(P<0.05)$, with a non-significant difference regarding serum SGPT $(P=0.1257)$. Compared to GI, there was a significant difference regarding serum GSH, MDA, SGOT $(P<0.001)$ in GIII. However, when compared to GII, there was a non-significant change regarding the same parameters. The difference between GIV and GI regarding serum GSH, MDA, SGOT, and SGPT was significant $(P<0.001)$, and there was also a significant difference when compared to GII regarding the same parameters inflammatory infiltration. Liver sections showed maintenance of hepatic architecture with minimal inflammatory infiltrate (Fig. 7).
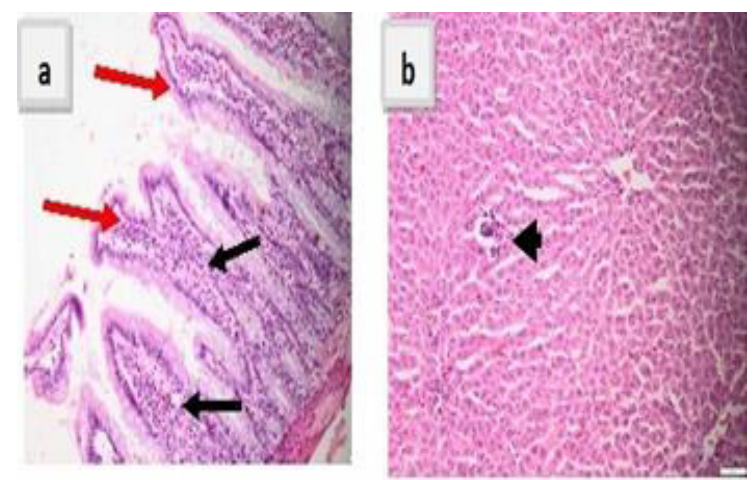

Fig. 7. a): Small intestinal sections in GV showing normal surface epithelium, with preserved goblet cells (red arrows). The lamina propria contains mild inflammatory infiltration (black arrows) (H\&E stain x200). b): Liver section showing normal architecture with mild dilatation and inflammatory infiltration of the portal tracts (black-arrow head) (H\&E stain $\mathrm{x} 200)$.

$(P<0.001)$. Similarly, GV versus GI showed a significant difference for the results of serum GSH and SGPT $(P<0.001)$ and a non-significant difference regarding serum MDA and SGOT, while GV versus GII showed a significant difference for the serum levels of GSH, MDA, SGOT, and SGPT $(P<0.001)$, also, there was a significant difference between GV and GIV regarding serum GSH, SGOT, SGPT $(P<0.001)$ and MDA $(P<0.05)$ (Table 2). The administration of PRP in GIII produced no significant changes in GSH, MDA, SGOT compared to positive control GII. Treatment with NTZ in GIV, and in addition to PRP in GV showed significant difference $(P<0.05)$.

Table 2. Biochemical changes of the different study groups.

\begin{tabular}{lcccc}
\hline \hline Groups & GSH & MDA & SGPT & SGOT \\
\hline I & $136.3 \pm 5.467$ & $2.060 \pm 0.2875$ & $47.07 \pm 0.8512$ & $51.09 \pm 0.9893$ \\
II & $91.71 \pm 2.080^{\mathrm{a}}$ & $3.920 \pm 0.5865^{\mathrm{a}}$ & $59.08 \pm 1.405^{\mathrm{a}}$ & $52.03 \pm 1.239$ \\
III & $93.91 \pm 3.527^{\mathrm{a}}$ & $3.780 \pm 0.5473^{\mathrm{a}}$ & $61.17 \pm 3.029^{\mathrm{a}}$ & $68.19 \pm 1.686^{\mathrm{ab}}$ \\
IV & $110.2 \pm 4.626^{\mathrm{ab}}$ & $2.950 \pm 0.3923^{\mathrm{ab}}$ & $41.09 \pm 1.166^{\mathrm{ab}}$ & $44.11 \pm 1.453^{\mathrm{ab}}$ \\
V & $123.1 \pm 1.567^{\mathrm{abc}}$ & $2.390 \pm 0.2331^{\mathrm{bc}}$ & $49.03 \pm 1.467^{\mathrm{bc}}$ & $40.06 \pm 0.7011^{\mathrm{abc}}$ \\
$\boldsymbol{P}^{\text {value }}$ & $\mathbf{0 . 0 0 2 7}^{*}$ & $\mathbf{0 . 0 4 0 0 *}^{*}$ & $\mathbf{0 . 0 0 1 9}$ & $\mathbf{0 . 1 2 5 7}$ \\
\hline
\end{tabular}

I: Non-infected, non-treated (negative control); II: Infected, non-treated (positive control); III: Infected and received PRP; IV: Infected and received NTZ; V: Infected received PRP and NTZ. Values are presented as mean \pm SD. @: One-way ANOVA and post hoc Tukey`s multiple comparison test. a: Significant difference between all groups and the negative control. b: Significant difference between GIII, GIV, and GV versus the positive control. c: Significant difference between GIV in comparison to GV. *: Significant $P<0.05$.

\section{DISCUSSION}

Cryptosporidium spp. are well-known parasites causing waterborne epidemics all over the world ${ }^{[43]}$. The outcome of cryptosporidiosis is greatly dependent on the immune status of the patient, giving clinical manifestations that vary greatly from mild self-limited diarrhea within two to three weeks in the immunocompetent patients, to severe life-threatening illness with dehydration and electrolyte imbalance in the immunocompromised patients ${ }^{[44-46]}$. Cryptosporidiosis is associated with high mortality among immunodeficient patients ${ }^{[77,48]}$. Also, cryptosporidiosis may lead to atypical clinical manifestations in immunodeficient patients such as pancreatitis, respiratory and biliary tract infections ${ }^{[49]}$. 
Tissue sections of the small intestinal ileocaecal junction from immunocompromised mice infected with cryptosporidiosis revealed short, broad, and atrophied intestinal villi with the reduction of the villous to crypt height ratio. Mucosal ulceration, goblet cell depletion, and inflammatory infiltration of the lamina propria were noted. Liver sections showed congested sinusoids with dilated fibrotic portal tracts ${ }^{[50]}$.

According to results of the present study, following cryptosporidiosis under immunocompromised conditions, treatment with the PRP showed significant improvement in the histopathological changes of small intestinal villi at the ileocaecal region and restored the liver architecture with reduction of portal tracts pathology. These results were marked when PRP was used in combination with NTZ giving results better than PRP injection alone, or NTZ administration alone.

Marx et $a l^{[51]}$ were the pioneers in studying PRP prepared by centrifugation of blood then separation of the supernatant that is very rich in platelets. Plateletrich plasma proved to contain many important GFs. It is a breakthrough in the field of medicine to discover the ability to use PRP in tissue regeneration as platelets contain proteins required for hemostasis as well as numerous $\mathrm{GFs}^{[52]}$ such as basic fibroblast growth factor (BFGF), platelet-derived growth factor (PDGF), transforming growth factor beta TGF- $\beta$, vascular endothelial growth factor (VEGF), endothelial growth factor (EGF), and insulin-like growth factor (IGF) ${ }^{[53,54]}$. Platelet-rich plasma also releases special chemokines and cytokines (e.g., IL-1 and platelet factor 4) in addition to important proteins and peptides (e.g., fibrinogen, fibronectin, osteonectin, osteocalcin, vitronectin, and thrombospondin). Therefore, many PRP types have been used by clinicians for years due to their enhancing effects on wound healing, cellular mitogenesis, osteogenesis, and angiogenesis ${ }^{[55]}$. Moreover, advocates of PRP treatment prefer PRP because of its beneficial effects in increasing tissue regeneration. Accordingly, it was used in reconstructive surgery to decrease the rate of postoperative necrosis and enhance healing, as well as lowering infection due to its antibiotic-like-action of contained leukocytes; in addition to decreasing pain and blood loss. Platelet-rich plasma is a cheap easily obtained product without any risk for rejection or harmful immune responses against $\mathrm{it}^{[56,57]}$. It was reported that PRP has a strong synergistic effect with adipose-derived stem cells on amelioration and healing in a mouse with induced pressure injury ${ }^{[58]}$. The use of PRP has been reported in many fields of medicine, including maxillofacial surgery and the treatment of problematic soft tissue ulcers ${ }^{[59,60]}$. Also, PRP became one of the best treatment options in the field of sports medicine for the treatment of tears in the rotator cuff, and the ulnar collateral ligament, hamstring injuries, in addition to knee osteoarthritis ${ }^{[61]}$. Also, transfusion of platelets can improve liver function in patients with chronic liver disease and cirrhosis due to their ability to produce many types of GFs in addition to the antifibrotic properties ${ }^{[62]}$. Platelet-rich plasma proved to reduce chemically induced liver fibrosis in experimental animals as it significantly diminished fibrotic areas and hepatic hydroxyproline in carbon tetrachloride (CCl4) induced hepatic fibrosis ${ }^{[52]}$. Also, Takahashi et al. ${ }^{[23]}$ found that human PRP lessened significantly the fibrotic index and hepatic hydroxyproline content in CCl4-initiated liver fibrosis in severe combined immunodeficient mice. Moreover, a recent study revealed that rat PRP markedly improved dimethylnitrosamine-induced liver fibrosis as demonstrated by significant lowering of liver hydroxyproline content ${ }^{[25,45]}$.

On the other hand, there is increasing evidence that PRP may be serious in patients with tumors as it may lead to enhancement of tumor progression due to the release of a large amount of $\mathrm{GFS}^{[63]}$. In the field of Parasitology, PRP successfully ameliorated the hepatic fibrosis in murine schistosomiasis mansoni. Although it did not significantly affect mean hepatic granuloma number, it caused a significant reduction in mean hepatic granuloma diameter in comparison with both infected untreated mice and praziquantel (PZQ) only treated mice. When PRP was combined with PZQ, the treatment produced the most noticeable decrease regarding granuloma diameter. The reducing effect of PRP on the granuloma diameter could be attributed to its anti-fibrotic action, besides, it may induce secretion of some mediators such as insulin-like growth factor-1 (IGF-1) and hepatocyte growth factor (HGF). The former, greatly stimulates hepatocyte proliferation, and is, therefore, considered the most significant mediator for liver regeneration ${ }^{[26,64]}$.

Glutathione has a significant role in the detoxification of oxygen free radicals produced at the inflammation sites ${ }^{[65]}$. A low level of GSH is of pathogenic importance in hepatic parasitic infections as in schistosomiasis. Accordingly, elevated GSH levels in target cells and the plasma might have a beneficial effect. Inhibition of oxidative stress and decreasing the intracellular peroxides level depend mainly on elevating the level of GSH and fosters its metabolizing enzymes to face the liberated free radicals ${ }^{[66]}$. In our study involving immunocompromised rats infected with Cryptosporidium spp., the MDA lipid peroxidation product was elevated, whereas the GSH level was reduced. This concurs with many studies in which there was liver affection in experimentally infected mice with $S$. mansoni ${ }^{[67-70]}$. In our study, biochemical measurements of GSH, MDA, SGOT and SGPT confirmed the beneficial therapeutic effect of NTZ against cryptosporidiosis. This concurs with the study stating that NTZ is the only Food and Drug Administrationapproved therapy, although it is not consistently effective for therapy of cryptosporidiosis in the majority of vulnerable patients ${ }^{[71]}$. In the present study, GV versus GI showed a non-significant difference regarding 
serum MDA and SGOT indicating the strong effect of the combination therapy in lowering their levels near to the normal values; and a significant difference regarding decreased serum GSH and SGPT, $(P<0.001)$. However, when compared to GII, there was a significant change in decreasing serum GSH, and SGPT with increasing serum levels of MDA and SGOT $(P<0.001)$.

Results of GV were better than GIV, being very similar to the negative control with a non-significant statistical difference regarding results of serum MDA and SGOT and had the best results between the study groups regarding serum GSH and SGPT compared to the negative control. This denotes the strong therapeutic effect for the PRP/NTZ combination that is superior to the effect of NTZ alone where there was a significant difference between GV and GIV regarding the results of serum GSH, SGOT, SGPT $(P<0.001)$, and MDA $(P<0.05)$. Accordingly, we could conclude that GV showed the best results due to statistically significant elevation of GSH with reduction of MDA, and SGOT indicating improvement compared to the GII. Also, GV showed a reduction of serum SGPT although there was statistically insignificant difference between the study groups. This is in agreement with the study that proved the strong synergistic effect of PRP with the adiposederived stem cells in inducing healing of tissues in mice exposed to pressure injury ${ }^{[58]}$. This also concurs with the usage of PRP-gel as an adjuvant treatment in human fibrosarcoma, to stimulate tissue repair and speed up recovery, thus impairing tumor growth and slowing tumor progress ${ }^{[72]}$. Similar conclusions were reported regarding the results of serum GSH, MDA, and SGOT when ginger (Zingiber Officinale) loaded nanoparticles were used in the treatment of murine schistosomiasis mansoni ${ }^{[70]}$. Hence, it seems that combination therapies will play an important role to ameliorate the pathologic effects of parasitic infections.

In conclusion, results of former studies ${ }^{[26,58,64,72]}$ in addition to the findings of the current research elucidate the important effects of PRP on tissue healing and fibrosis reduction that could be considered a breakthrough in the treatment of the pathologic changes following parasitic infections. Although the PRP therapy had no direct effect on the parasite, our results indicated that PRP could be considered as a novel potential adjuvant therapy with NTZ to ameliorate the pathologic and inflammatory effects of cryptosporidiosis on the small intestinal villi and on the liver and portal tracts in the immunocompromised hosts.

Acknowledgment: We would like to acknowledge the Animal Research Institute in Giza governorate, Egypt for their sincere help and support by providing us with the Cryptosporidium spp. oocysts.

Author contribution: El-Kholy WAMS designed the plan of work, performed the practical part, and shared in writing and revising the manuscript. Elgohary SA performed the histopathological study. El-Ashkar
AM shared in designing the plan of work, analyzing the data, writing, and revising the manuscript. The manuscript has been read and approved by all named authors. We further confirm that the order of authors listed has been approved by all of us.

Conflicts of interest: None.

Financial support: There has been no financial support for this work that could have influenced its outcome.

\section{REFERENCES}

1. Dumenil G. Revisiting the extracellular lifestyle. Cell Microbiol 2011; 13(8):1114-1121.

2. Pita-Fernández L, Vargas-Castrillón J, Pazos C, Gallegod I, García-Monzón C. Colitis por Cryptosporidium como forma de presentación en un paciente con síndrome de inmunodeficiencia adquirida. Rev Esp Enfermedades Dig 2006; 98(8):621-623.

3. Pedersen $\mathrm{SH}$, Wilkinson AL, Andreasen A, Warhurst DC, Kinung'hi SM, Urassa M, et al. Cryptosporidium prevalence and risk factors among mothers and infants 0 to 6 months in rural and semi-rural Northwest Tanzania: A Prospective Cohort Study. PLoS Negl Trop Dis 2014; 8(10): e3072.

4. Del Coco VF, Córdoba MA, Bilbao G, de Almeida Castro AP, Basualdo JA, Fayer R, et al. Cryptosporidium parvum GP60 subtypes in dairy cattle from Buenos Aires, Argentina. Res Vet Sci 2014; 96(2):311-314.

5. Ryan U, Hijjawi N. New developments in Cryptosporidium research. Inter J Parasitol 2015; 45:367-373.

6. Bouzid M, Tyler KM, Christen R, Chalmers RM, Elwin K, Hunter PR. Multi-locus analysis of human infective Cryptosporidium species and subtypes using ten novel genetic loci. BMC Microbiol 2010;10:213.

7. Cacciò SM. Molecular epidemiology of human cryptosporidiosis. Parassitologia 2005; 47(2):185-192.

8. Chalmers RM, Smith R, Elwin K, Clifton-Hadley FA, Giles M. Epidemiology of anthroponotic and zoonotic human cryptosporidiosis in England and Wales, 2004-2006. Epidemiol Infect 2011; 139(5):700-712.

9. Guk SM, Seo M, Park YK, Oh MD, Choe KW, Kim JL, et al. Parasitic infections in HIV-infected patients who visited Seoul National University Hospital during the period 1995-2003. Korean J Parasitol 2005; 43(1):1-5.

10. Genta RM, Chappell CL, White AC, Kimball KT, Goodgame RW. Duodenal morphology and intensity of infection in AIDS-related intestinal cryptosporidiosis. Gastroenterology 1993; 105(6):1769-1775.

11. Mccole DF, Eckmann L, Laurent F, Kagnoff MF. Intestinal epithelial cell apoptosis following Cryptosporidium parvum infection. Infect Immun 2000; 68(3):1710-1713.

12. Laurent F, Kagnoff MF, Savidge TC, Naciri M, Eckmann L. Human intestinal epithelial cells respond to Cryptosporidium parvum infection with increased prostaglandin $\mathrm{H}$ synthase 2 expression and prostaglandin E2 and F2 alpha production. Infect Immun 1998; 66(4):1787-1790.

13. Elewaut D, DiDonato JA, Kim JM, Truong F, Eckmann L, Kagnoff MF. NF-kappa B is a central regulator of 
the intestinal epithelial cell innate immune response induced by infection with enteroinvasive bacteria. J Immunol 1999; 163(3):1457-1466.

14. Amadi B, Mwiya M, Sianongo S, Payne L, Watuka A, Katubulushi $\mathrm{M}$, et al. High dose prolonged treatment with nitazoxanide is not effective for cryptosporidiosis in HIV positive Zambian children: A randomized controlled trial. BMC Infect Dis 2009; 9:195.

15. Cabada MM, White AC. Treatment of cryptosporidiosis: Do we know what we think we know? Curr Opin Infect Dis 2010; 23(5):494-499.

16. Abubakar I, Aliyu SH, Arumugam C, Usman NK, Hunter PR. Treatment of cryptosporidiosis in immunocompromised individuals: Systematic review and meta-analysis. Br J Clin Pharmacol 2007; 63(4):387-393.

17. Abubakar I, Aliyu SH, Arumugam C, Hunter PR, Usman NK. Prevention and treatment of cryptosporidiosis in immunocompromised patients. Cochrane Database of Systematic Reviews. John Wiley and Sons Ltd; 2007.

18. Petrungaro PS. Using platelet-rich plasma to accelerate soft tissue maturation in esthetic periodontal surgery. Compend Contin Educ Dent 2001; 22(9):729-732.

19. Bennett NT, Schultz GS. Growth factors and wound healing: biochemical properties of growth factors and their receptors. Am J Surg 1993;165(6):728-737.

20. Anitua E, Andia I, Ardanza B, Nurden P, Nurden AT. Autologous platelets as a source of proteins for healing and tissue regeneration. Vol. 91, Thrombosis and Haemostasis. Thromb Haemost; 2004; 91(1):4-15.

21. El-Sharkawy H, Kantarci A, Deady J, Hasturk H, Liu H, Alshahat M, et al. Platelet-rich plasma: growth factors and pro- and anti-inflammatory properties. J Periodontol 2007; 78(4):661-669.

22. Weiskirchen R, Tacke F. Liver fibrosis: From pathogenesis to novel therapies. Dig Dis 2016; 34(4):410-422.

23. Takahashi K, Murata S, Fukunaga K, Ohkohchi N. Human platelets inhibit liver fibrosis in severe combined immunodeficiency mice. World J Gastroenterol 2013; 19(32):5250-5260.

24. Shoeib HM, Keshk WA, Foda AM, Abo El Noeman SAEDE. A study on the regenerative effect of platelet-rich plasma on experimentally induced hepatic damage in albino rats. Can J Physiol Pharmacol 2018; 96(6):630-636.

25. Salem NA, Hamza A, Alnahdi H, Ayaz N. Biochemical and molecular mechanisms of platelet-rich plasma in ameliorating liver fibrosis induced by dimethyl nitrosourea. Cell Physiol Biochem 2018; 47(6):23312339.

26. El-Aswad BW, El-Refai SA, Mahmoud SF, Helwa MA. Human platelet-rich plasma alleviates liver fibrosis in murine schistosomiasis mansoni. Med J Cairo Univ 2018; 86(7):3807-3823.

27. Maia L, Souza M. Components rich in platelets in the repair of disorders having osteoarticular and ligamentous in animals. Ciência Rural 2009; 39(4):1267-1274.

28. Harp J, Wannemuehler MWD, Moon H. Susceptibility of germfree or antibiotic-treated adult mice to Cryptosporidium parvum. Infect Immun. 1988; 56(8):2006-2010.
29. Fayer R, Guidry A, Blagburn BL. Immunotherapeutic efficacy of bovine colostral immunoglobulins from a hyperimmunized cow against cryptosporidiosis in neonatal mice. Infect Immun1990; 58(9):2962-2965.

30. Bjorneby JM, Hunsaker BD, Riggs MW, Perryman LE. Monoclonal antibody immunotherapy in nude mice persistently infected with Cryptosporidium parvum. Infect Immun 1991; 59(3):1172-1176.

31. Bhagat M, Sood S, Yadav A, Verma P, Manzoor N, Chakraborty D, et al. Alterations in oxidative stress parameters and its associated correlation with a clinical disease on experimental Cryptosporidium parvum infection in Swiss albino mice. J Parasit Dis 2017; 41(3):707-712.

32. Tarazona R, Blewett DA, Carmona MD. Cryptosporidium parvum infection in experimentally infected mice: Infection dynamics and effect of immunosuppression. Folia Parasitol (Praha) 1998; 45(2):101-107.

33. Li X, Brasseur P, Agnamey P, Leméteil D, Favennec L, Ballet JJ, et al. Long-lasting anticryptosporidial activity of nitazoxanide in an immunosuppressed rat model. Folia Parasitol (Praha) 2003; 50(1):19-22.

34. Franco D, Franco T, Schettino AM, Filho JMT, Vendramin FS. Protocol for obtaining platelet-rich plasma (PRP), platelet-poor plasma (PPP), and thrombin for autologous use. Aesthetic Plast Surg 2012; 36(5):1254-1259.

35. Barnes J, Paget G. Mechanisms of toxic action. Prog Med Chem 1965;4:18-38.

36. Henricksen S, Pohlenz J. Staining of Cryptosporidium by a modified Ziehl-Neelsen technique. Acta Vet Scand 1981; 22(3-4):594-596.

37. Garcia LS (Editor). Clinically important human parasites: Intestinal protozoa: Cryptosporidium spp. In: Diagnostic Medical Parasitology. $5^{\text {th }}$ ed ASM Press Washington, DC; 2007.

38. Benamrouz S, Guyot K, Gazzola S, Mouray A, Chassat T, Delaire B et al. Cryptosporidium parvum infection in SCID Mice Infected with only one oocyst: qPCR assessment of parasite replication in tissues and development of digestive cancer. PLoS ONE 2012; $7(12): \mathrm{e} 51232$.

39. Schmidit E, Schmidit F. Kline Enzyme Fiebel Schriftenreihe. $3^{\text {rd }}$ ed. Diagnostic Boehringer Mannheim 1981.

40. Ohkawa H, Ohishi N, Yagi K. Assay for lipid peroxides in animal tissues by thiobarbituric acid reaction. Anal Biochem 1979; 95(2):351-358.

41. Bergmeyer $\mathrm{H}$, Herder $\mathrm{M}$, Rej R. Approved recommendation on IFCC methods for the measurement of catalytical concentration of enzymes. Part 2- IFCC method for aspartate aminotransferase. J Clin Chem Clin Biochem 1986; 24:497-499.

42. Feldman AT, Wolfe D. Tissue processing and hematoxylin and eosin staining. Methods Mol Biol 2014; 1180:31-43.

43. Karanis P, Kourenti C, Smith H. Waterborne transmission of protozoan parasites: A worldwide 
review of outbreaks and lessons learnt. J Water Heal 2007; 5:1-38.

44. O'Donoghue PJ. Cryptosporidium and cryptosporidiosis in man and animals. Int J Parasitol 1995; 25(2):139195.

45. Blackburn BG, Craun GF, Yoder JS, Hill V, Calderon $\mathrm{RL}$, Chen N, et al. Surveillance for waterborne-disease outbreaks associated with drinking water-United States, 2001-2002. MMWR Surveill Summ Morb Mortal Wkly report Surveill Summ/CDC 2004; 53(8):23-45.

46. Chen X-M, Keithly JS, Paya CV, LaRusso NF. Cryptosporidiosis. N Engl J Med 2002; 346(22):17231731.

47. Juranek DD. Cryptosporidiosis: sources of infection and guidelines for prevention. Clin Infect Dis 1995;21:5761.

48. Manabe YC, Clark DP, Moore RD, Lumadue JA, Dahlman HR, Belitsos PC, et al. Cryptosporidiosis in patients with AIDS: Correlates of disease and survival. Clin Infect Dis 1998; 27(3):536-542.

49. Hunter PR, Nichols G. Epidemiology and clinical features of Cryptosporidium infection in immunocompromised patients. Clin Microbiol Rev 2002; 15:145-154.

50. Abdelmaksoud HF, El-Ashkar AM, Elgohary SA, ElWakil ES. Potential therapeutic and prophylactic effects of Asafoetida in murine cryptosporidiosis. J Parasit Dis 2020; 44(3):646-653.

51. Marx RE, Carlson ER, Eichstaedt RM, Schimmele SR, Strauss JE, Georgeff KR. Platelet-rich plasma: Growth factor enhancement for bone grafts. Oral Surg Oral Med Oral Pathol Oral Radiol Endod 1998;85: 638-646.

52. Hesami Z, Jamshidzadeh A, Ayatollahi M, Geramizadeh B, Farshad O, Vahdati A. Effect of platelet-rich plasma on CCl 4 -induced chronic liver injury in male rats. Int J Hepatol 2014; 2014:1-7.

53. Rožman P, Bolta Z. Use of platelet growth factors in treating wounds and soft-tissue injuries. Acta Dermatovenerol Alp Pannonica Adriat 2007; 16:156165.

54. Mazzucco L, Balbo V, Cattana E, Guaschino R, Borzini P. Not every PRP-gel is born equal evaluation of growth factor availability for tissues through four PRP-gel preparations: Fibrinet ${ }^{\circledR}$, RegenPRP-Kit ${ }^{\circledR}$, Plateltex ${ }^{\circledR}$, and one manual procedure. Vox Sang 2009; 97(2):110118.

55. Aydin O, Karaca G, Pehlivanli F, Altunkaya C, Uzun $\mathrm{H}$, Özden $\mathrm{H}$, et al. Platelet-rich plasma may offer new hope in suppressed wound healing when compared to mesenchymal stem cells. J Clin Med 2018; 7(6):143.

56. Pallua N, Wolter T, Markowicz M. Platelet-rich plasma in burns. Burns 2010; 36:4-8.

57. Bielecki TM, Gazdzik TS, Arendt J, Szczepanski T, Król W, Wielkoszynski T. Antibacterial effect of autologous platelet gel enriched with growth factors and other active substances: An in vitro study. J Bone Jt Surg 2007; 89(3):417-420.

58. Liu Z, Xiao S, Tao K, Li H, Jin W, Wei Z, et al. Synergistic effects of human platelet-rich plasma combined with adipose-derived stem cells on healing in a mouse pressure injury model. Stem Cells Int 2019; 2019:3091619.

59. Mitra A, Mishra L, Li S. EMT, CTCs and CSCs in tumor relapse and drug-resistance, Oncotarget. Impact Journals LLC 2015; 6:10697-10711.

60. Nurden AT, Nurden P, Sanchez M, Andia I, Anitua E. Platelets and wound healing. Front Biosci 2008; 13:3532-3548.

61. Mlynarek R, Kuhn A, Bedi A. Platelet-rich plasma (PRP) in orthopedic sports medicine. Am J Orthop (Belle Mead NJ) 2016; 45(5):290-326.

62. Maruyama T, Murata S, Takahashi K, Tamura T, Nozaki $\mathrm{R}$, Ikeda $\mathrm{N}$, et al. Platelet transfusion improves liver function in patients with chronic liver disease and cirrhosis. Tohoku J Exp Med 2013; 229(3):213-220.

63. Pisters PW, Leung DH, Woodruff J, Shi W, Brennan MF. Analysis of prognostic factors in 1,041 patients with localized soft tissue sarcomas of the extremities. J Clin Oncol 1996; 14(5):1679-1689.

64. Maruyama T, Ohkohchi N. Platelets and liver regeneration. Seikagaku. Seikagaku; 2012; 84:693698.

65. Liang YJ, Luo J, Yuan Q, Zheng D, Liu YP, Shi L, et al. New insight into the antifibrotic effects of praziquantel on mice in infection with Schistosoma japonicum. PLoS One 2011;6(5) : e20247.

66. Pocernich CB, La Fontaine M, Butterfield DA. In vivo glutathione elevation protects against hydroxyl free radical-induced protein oxidation in rat brain. Neurochem Int 2000; 36(3):185-191.

67. El-Sokkary GH, Omar HM, Hassanein AFMM, Cuzzocrea $\mathrm{S}$, Reiter RJ. Melatonin reduces oxidative damage and increases survival of mice infected with Schistosoma mansoni. Free Radic Biol Med 2002; 32(4):319-332.

68. Mahmoud MR, El-Abhar HS, Saleh S. The effect of Nigella sativa oil against the liver damage induced by Schistosoma mansoni infection in mice. J Ethnopharmacol 2002; 79(1):1-11.

69. Ahmed M, Mostafa O. Experimental use of black seed oil against Schistosoma mansoni in albino mice. IV. Oxidative stress markers and some biochemical parameters in liver and kidney. J Egy Ger Soc Zool 2003; 41:227-253.

70. EL-Derbawy M, ELKholy W, Baiuomy I, Salem H. A study of the potential therapeutic effect of ginger (Zingiber Officinale) loaded nanoparticles on murine schistosomiasis mansoni. J Egypt Soc Parasitol 2019; 49(1):123-128.

71. Chavez MA, White AC. Novel treatment strategies and drugs in development for cryptosporidiosis. Expert Review of Anti-Infective Therapy. Taylor and Francis Ltd 2018;16:655-661.

72. Barbieri A, Bimonte S, Loquercio G, Rea D, Cascella M, Anniciello A, et al. The effects of the use of plateletrich plasma gel on local recurrence in an animal model of human fibrosarcoma. Infect Agent Cancer 2019; 14(1):1-7. 